\title{
ASSESSMENT OF PROCESS MANAGEMENT MATURITY IN DEVELOPING COUNTRIES BASED ON SAW METHOD
}

\author{
Marija RADOSAVLJEVIC \\ Atkinson Graduate School of Management, Willamette University, \\ 900 State Street, Salem, Oregon, USA \\ Faculty of Economics, University of Nis, \\ Trg kralja Aleksandra Ujedinitelja 11, Nis 18000, Serbia \\ E-mail:mandelko@willamette.edu,marijaandjelkovic2003@yahoo.com
}

Received 17 April 2013; accepted 11 June 2013

\begin{abstract}
Business process management is a comprehensive, holistic management approach, aligned with the context that proceeds from globalized economy. The extent to which this approach is present in an organization represents its process management maturity. Process management maturity has drawn attention of authors and, consequently, a lot of maturity models have appeared. These models incorporate elements, which determine the level of organizations' maturity. Earlier research results indicate that those elements are mutually related and responsible for organizations' performances. Since those results mostly refer to developed countries, the question is whether conclusions that proceed from them are valid for developing countries too. In order to answer this question, research has been conducted in Serbia. The aim of the research is to discover which maturity model elements represent the weak points of business process management in Serbian organizations, but also to evaluate the dependence of organizations' performances on process management maturity level. The analysis is based on statistics tools and Simple Additive Weight (SAW) method. Research results indicate that the maturity level of the Serbian economy is not enviable. In addition, results suggest that business performances might be connected to process management maturity, in the sense that higher maturity level means higher performances.
\end{abstract}

Keywords: process management, maturity, dominant elements, assessment, developing countries, ANOVA, SAW method.

JEL Classification: M21, D22, O12.

\section{Introduction}

Business process management is an important issue of any organization which wants to provide sustainable performance improvement. It is defined as a holistic management approach that focuses on identifying, defining, implementing, measuring, monitoring, analysing and continuously improving business processes (Power 2007), based on integration of process design and application of appropriate information technology. 
The management concept based on process orientation, presented through process maturity levels, became popular at the beginning of XXI century. However, measurement of process performances dates back from 1930s in Shewart's control charts. He became famous for his work Statistical Method from the Viewpoint of Quality Control (Shewhart 1939), which shows that process management and quality management cannot be observed separately. Shewhart's ideas were further developed and popularized by Deming and Juran. According to Deming, quality is ensured through continuous process improvement, which involves reducing variation in processes, and, consequently, variation in quality of the process results (Deming 1982). According to Juran, each participant in a value chain is an internal customer from the perspective of the previous one, and supplier for the next one. Thus, at each sequence of value chain the three roles model may be used. Those roles are: supplier, process (or) and user (Juran 1992). Through this model, it is possible to decompose value chain into processes and sub-processes, where each process represents an opportunity for improvement of the whole value chain. The ideas and methods proposed by those three authors represent the basis for Total Quality Management (TQM).

In addition, before process maturity models, another concept based on process management was introduced. It is the Six Sigma concept, which points out process significance in two ways: first, this concept is focused on continual improvement of process quality, and second, this concept suggests process approach to process improvement (DMAIC process). Therefore, the Six Sigma concept represents another step in quality management evolution started by Shewhart, and confirms that quality management results are conditioned with process orientation.

Soon after the appearance of the Six Sigma concept another business concept became very popular. The end purpose of this concept is similar, but the way it suggests achieving higher level of performance is quite different compared to the Six Sigma concept (it assumes radical improvement, while Six Sigma assumes continual, but incremental improvement). It's authors, Hammer and Champy, explained business process reengineering (BPR) as "the fundamental rethinking and radical redesign of business processes to achieve dramatic improvements in critical, contemporary measures of performance, such as cost, quality, service and speed" (Hammer, Champy 1993).

Today there are a lot of models that describe business process management maturity (BPMM). They all describe the evolutionary path that leads an organization through different states of maturity, towards business excellence. The first one, who has actually introduced the business process management model, is Watts Humphrey (1988). The basic assumption of this model is that organizations in which processes are systematically managed and performed are more capable to respond to customer demands, compared to traditionally managed organizations (Harmon 2008). At the time when the maturity model appeared, some authors observed business process management as a critical success factor of Enterprise Resource Planning (ERP) implementation (Gulledge, Sommer 2002). On the other hand, some authors (Lewellyn, Armistead 2000: 225) describe components of the process in maturity model as interrelated activities, similarly like 
BPR. Finally, there are authors that see process management maturity as a product of TQM and BPR combination (Lewellyn, Armistead 2000). The significance of BPMM and its connection with BPR has been also emphasized by Maull et al. (2003). They studied the reengineering process in 33 organizations and identified three reengineering programs: the strategic, process and cost-based. According to them, cost reduction and process approach are very important for starting the journey towards process maturity, but the strategic aspect is necessary for reaching high level of maturity.

Hertz, Johansson and De Jager (2001) formulated the business process management model containing stages of maturity. Their model has three stages of maturity, where each stage is a combination of orientation (production, cost, and network) and organizational focus (functional, project, and process). Fisher presented the maturity model as two-dimensional. Processes are observed from dimensions marked as elements and process maturity levels (Fisher 2004: 6). The model developed by Rosemann and de Bruin (2004) includes an observation of six elements during the five stages (maturity stages) an organization has to pass in order to reach the highest level of BPMM.

Another business process maturity model appeared in 2005 and was promoted by Weber et al. (2005). They identified the following five maturity levels: Initial, Managed, Standardized, Predictable, Innovating, claiming that improvement achieved at each level is the basis for further improvement and reaching the next maturity level. According to them BPMM describes an evolutionary improvement path that guides organizations in moving from immature, inconsistent processes to mature, disciplined processes (Weber et al. 2005).

Another well-known process management model is Hammer's model. Hammer (2007) also accepts the phase approach to process management and emphasizes that all previous stages must be fully completed before reaching the next stage (the higher maturity level). Hammer's model clearly highlights the difference between process maturity and the organization maturity (business processes management maturity). In order to analyse process performances, the model takes into account the maturity of five drivers: design (purpose, context and documentation), performers - implementers (knowledge, skills and behaviour of employees during the process realization), owner (identity, activity and authority), infrastructure (information systems and human resources) and measures (definition and use). When it comes to an organization's maturity, Hammer emphasizes the following four skills (Power 2007): leadership (awareness, commitment, style, and behaviour), culture (team work, focus on customers, responsibility and attitude towards change), expertise (staff and methodology) and the way of managing (process model, responsibility, integration).

Most of the introduced process maturity models are based on the same principle, which is sometimes referred to as "staged sequence of levels" (Röglinger et al. 2012) and as such are very similar to each other (Andjelkovic Pesic 2009). For example, between the model proposed by Weber, Curtis, Gardiner and Hammer and the model introduced by Rosemann and de Bruin there are minor differences. It might be said that they have the same focus and idea, but are aimed to different context or culture. 


\section{Process management maturity model: achieved results}

Business process management models are widely accepted in developed countries. Researchers in this field (Fisher 2004) were interested whether some BPMM elements are more important for transition between certain maturity levels or for reaching higher maturity levels. Also, some authors have been trying to find out if BPMM models provide improvement of organizations' performances and how their usefulness can be explained and proven. For example, a research with purpose to identify presence of process management tools and models in business practice was conducted in Germany, Austria and Switzerland in 2006. In the observed sample, throughout the German-speaking territory, TQM was implemented by $34 \%$ and Six Sigma by $24 \%$ of the total number of organizations (Neubauer 2009). Some authors' findings (Staples, Niazi 2008) indicate that organizations adopt maturity models in order to improve their product quality and project performance (e.g. development time, development cost, and productivity), but also to improve process management (e.g. process visibility and process measurement). Hung presented results of the research which confirmed that Process Alignment and People Involvement, as BPMM elements, are positively associated with organizational performance (Hung 2006). Some authors presented more precise results, claiming that direct process performance measures, such as cycle times and inventory levels, are also related to the maturity level (Lockamy, McCormack 2004). The conclusions based on other authors' results support hypothesis that improving processes maturity leads to business benefits (Sommerville, Ransom 2005). Some authors list the following as benefits from the implementation of the maturity model: a more disciplined management, improved project controllability and product quality (Wu et al. 2006). Some other authors point out additional qualitative benefits of maturity models, such as analysis of strengths and weaknesses of current business process management and development of "to-be" models in function of an organization's business objective achievement (Lee et al. 2007). The findings of Rosemann and De Bruin also confirm that the maturity model has potential to be very beneficial to organisations wishing to progress process management initiatives (Rosemann, De Bruin 2005).

Though business process management models have provided results for organizations that have implemented them in developed countries, there is still a slow (and at times a very rare) adoption of BPMM in developing countries (www.bpm.scitech.qut.edu.au). In addition, research in those countries is very rare, but the results are in line with the results from research conducted in developed countries. The results of research conducted in one of developing countries show that there are strong positive correlations between the variables examined that account for a higher level of maturity and performance of organization processes. Some authors have noticed a gap in emerging countries in the sense that business process management literature needs much more attention from scholars. The same impression is gained based on preliminary analysis of the situation in the Serbian economy. According to research results (Andjelkovic 2009; Andjelkovic et al. 2012) Serbian organizations cannot report using process management practice. In addition, when some of the results from developed countries are compared to the results of research conducted in Serbia it may be noticed that the situation in Serbia is 
not favourable. For instance, research conducted in Serbia showed that TQM was implemented by $31.6 \%$ and Six Sigma by only $3.3 \%$ of sampled organizations (Andjelkovic Pesic et al. 2012), which is lower compared to previously shown results for the German speaking area, published by Neubauer (2009).

\section{Research framework and hypotheses}

Bearing in mind the previously mentioned findings, which indicate positive relationship between business process management models and organizations' performances, the motive behind the research presented in this paper is to evaluate the level of BPMM in organizations in Serbia and to remind managers that there are concepts, methodologies and tools that can significantly facilitate business management.

The objective of the research is to discover which elements represent the weak points of the business process management in organizations in Serbia and, therefore, which elements deserve greater attention and focus of managers. Also, the objective of the research is to evaluate whether organizations with more mature process management have higher business results. In order to accomplish defined objectives, the following hypotheses have been formulated:

H1: There is no difference between dominant elements at certain maturity levels in developed and developing countries,

H2: All process management maturity model elements are at the same maturity level,

H3: All process management maturity model elements are correlated,

H4: Higher process management maturity level means higher level of business performances.

As it is pointed out, most of the so-far research regarding business process management was conducted in developed countries. Therefore, results indicate elements that may be considered the leading factors at certain maturity levels for reaching the following maturity levels. Therefore, the first hypothesis (H1) refers to the difference between elements that pre-dominate certain maturity levels in developed and developing countries, where such predomination represents their power to initiate attaining the next maturity level.

The second hypothesis (H2) is formulated based on research conducted by Fisher (2004) and Spanyi (2004) and their observation about the non-linear character of BPMM model elements. Those authors claim that BPMM model elements are not necessarily at the same maturity level. This means that some elements may be at higher maturity level, acting as drivers of change (improvement), while others may be at lower maturity level, representing limitations of change (improvement).

One of the purposes of BPMM model formulated by Rosemann and De Bruin is to enable future research into relationships and correlation between factors to improve understanding of BPM issues (De Bruin, Rosemann 2005). This means that they assumed that there is correlation between factors influencing the business process maturity level. Since they did not have empirical evidence for the correlation between the factors of the BPMM model and BPM success, they encouraged research which will provide 
this empirical evidence. Therefore, the third hypothesis (H3) considers the correlation between BPMM model elements.

The fourth hypothesis (H4) proceeds from the results of the researches conducted by different authors in developed countries (Sommerville, Ransom 2005, Rosemann, De Bruin 2005, Hung 2006, Staples, Niazi 2008), who either expressed doubt about the relationship between maturity level and business performances or confirmed it based on empirical research.

Models formulated by De Bruin et al. (2005) and Ravesteyn et al. (2012) were used as basis for establishing the framework for evaluation of the process management maturity level in the Serbian economy and for formulating the questionnaire for the empirical research. Basic postulates for the evaluation of the process management maturity remained the same as in models proposed by the aforementioned authors (Strategic alignment, Governance, Methods, Information technology (IT), People and Culture), but their elements and sub-elements are slightly adapted in order to be more comprehensible to managers of organizations in Serbia (Appendix). More specifically, for the purpose of this research, on the basis of previous research, the original maturity model has been transformed in a way that Governance and Methods are merged into one element called Process Awareness and Measurement (since some sub-elements of those two elements were unknown for the managers interviewed). This fact is the first indicator of unenviable process management maturity in Serbia, since operational tools obstacles were seen as disturbing factors of process integration (Forslund, Jonsson 2009).

A questionnaire was sent to 600 randomly chosen organizations. 132 completed samples were returned, indicating a response rate of $22 \%$. Most of the organizations that were unwilling to participate in this research claimed that they are not familiar with BPMM models and that they have not adopted process orientation. The sample size is not sufficient to declare the sample as representative, but it certainly can be considered informative for getting insight into the presence of process orientation in organizations in Serbia. It is expected that this research has another positive effect: the benefits that individual organizations may have gained as a result of this research. Namely, managers of the organizations which participated in this research had the opportunity to assess the current situation of their respective organizations, based on their feedback. This may be an initial impulse for their greater interest in process orientation and focus on elements which, according to them, represent the weakest links in the value chain from a process-oriented perspective. On the other hand, managers of individual organizations have the opportunity to compare their own results with the overall research results and to find out where exactly they stand in comparison to others.

\section{Evaluation of process management maturity: research results and discussion}

In this analysis BPMM level is observed as a dependent variable, depending on the maturity level of model elements (Strategic alignment, Process awareness and measurement, IT, People management, Culture), which are therefore independent variables, as 
in other research (McCormack 2009), but with doubt that they are mutually correlated. Before any analysis of the data collected, Cronbach's Alphas were calculated in order to evaluate internal consistency (Zafiropoulos, Vrana 2008). Crhonbach's Alpha value depends on average inter-item correlation. According to Trochim (2001), data may be considered reliable for analysis if Cronbach's Alpha total value (in this case for all 25 items, five elements and five sub-elements for each element) is higher than 0.70 . The reliability might be considered acceptable if we take into account the fact that Cronbach's Alpha for the data collected for this research is equal to 0.939 , and at the same time the Cronbach's Alphas for all individual items are also higher than 0.70 , but lower than 0.939 , meaning that they should not be excluded from the analysis.

The overall results indicate that the average maturity level for BPMM elements in Serbia is between 2 and 3, which corresponds to so-called frequently performing process management, where the maturity level is between 2-4 level (Wolf, Harmon 2012). This could be considered a good result, in comparison to the average in developed countries (between 2 and 4 maturity level).

One of the hypotheses concerns the domination of maturity elements at maturity levels in the sense that they may be observed as levers of change or transition to the higher maturity level. Precisely it is formulated as:

H1: There is no difference between dominant elements at certain maturity levels in developed and developing countries.

In order to determine which element dominates at corresponding maturity level and therefore it is critical for reaching the next maturity level, frequency measure was used. In this case, frequency represents the number of enterprises that have indicated an element as dominant at certain maturity level. The highest frequency indicates the element that is dominant for specific maturity level (Table 1). The benchmarking indicates that elements which dominate in Serbian enterprises at different maturity levels are almost identical to the results from developed countries. This slight difference indicates that the business culture is the element which is harder to adjust (improve) in Serbian enterprises compared to the enterprises in developed countries, as well as that managers, beside strategic alignment, consider IT as highly important for reaching the fifth maturity level. As is the case with Serbian enterprises, IT is a significant limitation due to facts perceived by other authors as well (Bazhenova et al. 2012). They are inapplicable of the standard software used in developed countries due to their high cost and lack of developed supporting infrastructure.

Table 1. Benchmarking of dominant elements

\begin{tabular}{lll}
\hline & \multicolumn{1}{c}{ Developed countries } & \multicolumn{1}{c}{ Developing countries (Serbia) } \\
\hline Second level & Culture and IT & IT \\
\hline Third level & Process awareness and measurement & Process awareness and measurement \\
\hline Forth level & People management & People management and Culture \\
\hline Fifth level & Strategic alignment & Strategic alignment and IT \\
\hline
\end{tabular}


The average maturity level for each element may be identified through descriptive statistics. Therefore, the mean has been calculated for maturity model elements in order to provide answer to the second hypothesis, formulated as:

H2: All process management maturity model elements are at the same maturity level.

Descriptive statistics shows that process management elements are not at the same maturity level. The least developed are IT (1.83) and Culture (2.15), while the most mature element is Process awareness and measurement (2.50), followed by People management (2.43). This result corresponds to previously stated results from developed countries (Hung 2006), confirming that managing processes and people are the key conditions for providing sustainable development in modern economy. Non-linear development of process management elements is not a strange situation. In fact, elements usually do not develop linearly (Fisher 2004; Spanyi 2004), and the purpose of maturity analysis precisely is to identify the ones that develop more slowly in order to focus on their improvement. In this case, the elements that are the weakest chains are IT and Culture. Since there is a difference in the average marks indicating maturity levels of elements, it might be useful to check whether those differences are statistically significant. The answer may be provided by ANOVA analysis. According to ANOVA results, significance level is 0.000 , which is lower than 0.05 . This means that there is statistically significant difference between the average marks of five elements describing process management maturity level. Furthermore, this means that business process management model elements are not equally developed or that they are not at the same maturity level.

Though there is statistically significant difference between process management model elements, this does not mean that they are not mutually correlated. In fact, if they were correlated, but there is a difference in their maturity level, this may indicate that more balanced development would mean easier transition from lower to upper maturity level. Therefore, correlation analysis concerns the third hypothesis:

H3: All process management maturity model elements are correlated.

The results of correlation analysis show that between Process awareness and measurement and People management there is the greatest, high positive correlation (0.840). These are also elements with the highest maturity level, which indicates that elements with high correlation coefficients may have the same maturity level. However, the correlation coefficients between other maturity model elements are also positive indicating high or medium correlation which means that the elements that are at lower maturity levels may be the limitation for further development of other elements, and for overall BPMM level.

The analysis based on descriptive statistics, correlation analysis, as well as ANOVA testing, may indicate overall maturity level concerning organizations in the sample. However, this analysis does not indicate whether higher maturity level means higher business performance level. Therefore, additional data and analysis are necessary to provide information whether to accept or reject the fourth hypothesis:

H4: Higher process management maturity level means higher level of business performances. 
For this purpose, as performance measure, profit per employee may be used. In the sample, average profit per employee amounts to $€ 12164.57$, with a standard deviation $€ 2643.09$. According to these measures, the category medium profit per employee means amount of average profit per employee in the interval $€ 12164.57 \pm € 2643.09$. In accordance with that, the category high profit per employee refers to average profit per employee $>€ 14807.66$ (€12164.57 + €2643.09), while the category low profit per employee refers to average profit per employee $<€ 9521.48$ (€12164.57 - €2643.09). According to this data, organizations in the sample have been grouped in the following way: the first group includes organizations with low profit per employee; the second includes organizations with medium profit per employee, while the third group includes organizations with high profit per employee.

One way to check whether there is a difference between those three groups of organizations is to compare the means of their elements' maturity level. For this purpose, ANOVA is used again. As in the case of comparing means of model elements, the results obtained with ANOVA suggest that there is a statistically significant difference between the three identified groups of organizations, according to process management model elements' maturity (significance level is 0.000, which is lower than 0.05).

In order to provide additional information for making a decision whether to accept or reject the fourth hypothesis, a multi-criteria method may be used. Three groups of organizations were compared by using the SAW method as multi-criteria analysis method. The SAW method aims at solving problems of choosing one of the series of $m$ alternatives $A i(i=1,2, \ldots, m)$ based on $n$ criteria $X j(j=1,2, \ldots, n)$. Each of the alternatives represents the vector $A i=\left(x_{i 1}, x_{\mathrm{i} 2}, \ldots, x_{i j} \ldots, x_{i n}\right)$, where $x i j$ is the value of the $j$-th attribute of the $i$-th alternative. For the purpose of this analysis, alternatives are groups or organizations, according to profit per employee, while criteria are process management maturity elements (Strategic alignment, Process awareness and measurement, IT, People management, Culture).

The problem of multi-criteria analysis is usually presented in a matrix form (Wisniewski 2006). The formulation of the multi-criteria model has been carried out in a few phases (Triantaphyllou 2000):

- Determining average marks for maturity elements and their sub-elements,

- Determining linearly normalized matrix,

- Determining average marks for maturity elements' and their sub-elements' significance,

- Determining weighted coefficients (based on significance),

- Determining the priority vectors.

Considering that one of the research objectives is to identify whether the higher maturity levels may be connected to higher performance level (profit per employee), beside evaluation of observed elements, managers were asked to evaluate the importance of mentioned process management model elements (and sub-elements). The importance of elements and sub-elements is used as a basis for determining weighted coefficients for SAW method application. In this case, the average importance was used (the average for all three groups of organizations), in order to avoid influence of significance on 
alternatives ranking (in that way ranking depends only on average marks of maturity model elements and sub-elements). Priority vectors represent sum-product of linearly normalized matrix elements and weighted coefficients for each group of organizations.

Data from Table 2 indicate that organizations from the second and third group have higher priority vectors compared to the first group. These results suggest that organizations that have higher maturity level of observed five elements, achieve higher financial performances (in this case, profit per employee). The thing that may be noticed is that the only element for which the third group of organizations has priority vector equal 1 is IT (due to the fact that for all five IT sub-elements, the third group of organizations has the highest values compared to the other two groups). Therefore it might be said that IT, as a maturity model element, is far more developed and present in the third group of organizations or that this element might be the weakest link in organizations that belong to the low-profit group.

Table 2. Priority vectors for BPMM elements

\begin{tabular}{cccccc}
\hline Elements & $\begin{array}{c}\text { Strategy } \\
\text { alignment }\end{array}$ & $\begin{array}{c}\text { Process awareness } \\
\text { and measurement }\end{array}$ & IT & $\begin{array}{c}\text { People } \\
\text { management }\end{array}$ & Culture \\
\hline Group I & 0.4994 & 0.5514 & 0.4869 & 0.5063 & 0.5629 \\
\hline Group II & $\mathbf{0 . 9 7 4 2}$ & 0.8370 & 0.6399 & 0.7611 & $\mathbf{0 . 9 7 9 9}$ \\
\hline Group III & 0.9585 & $\mathbf{0 . 9 7 4 4}$ & $\mathbf{1 . 0 0 0 0}$ & $\mathbf{0 . 9 8 8 5}$ & 0.9405 \\
\hline
\end{tabular}

Since priority vectors for the second and the third group or organizations have similar values, in determining the final rank of the three observed alternatives (three groups of organizations), it is necessary to weigh linear normalized values of priority vectors from Table 2. Weighted coefficients are calculated as average weighted coefficients for each maturity model element. Priority of alternatives (for each of model elements) is identified as s a sum-product of priority vectors for model elements, shown in Table 2, and corresponding weighted coefficients (Table 3).

Table 3. Average marks for BPMM elements' significance, weighed coefficients and priority vector

\begin{tabular}{lccccr}
\hline Elements & $\begin{array}{c}\text { Strategy } \\
\text { alignment }\end{array}$ & $\begin{array}{c}\text { Process awareness } \\
\text { and measurement }\end{array}$ & IT & $\begin{array}{c}\text { People } \\
\text { management }\end{array}$ & Culture \\
\hline \multicolumn{5}{c}{ Average marks of elements' significance } \\
\hline 3.2496 & 4.3323 & 4.0406 & 3.9895 & 3.8316 \\
\hline \multicolumn{7}{c}{ Weighted coefficients } \\
\hline Group I & 0.2228 & 0.2078 & 0.2052 & 0.1971 \\
\hline Group II & \multicolumn{7}{c}{ Priority vector } \\
\hline Group III & \multicolumn{5}{c}{0.5223} \\
\hline \multicolumn{5}{c}{0.8316} \\
\hline
\end{tabular}


From the final rank of the alternatives it is implied that the third group has rank one, since total priority vector is the highest, the second group has rank two, while the first group of organizations has rank three. Therefore, organizations from the third group, i.e. organizations with the highest profit per employee are at the same time the ones with the highest BPMM level. This conclusion is in accordance with other studies from developed countries (Skalle et al. 2009), indicating that results of the implementation of the BPMM model are visible through key performance indicators and are also felt by customers.

\section{Conclusions, limitations and directions for future research}

Process management maturity model should help managers to identify BPMM level and eventually take the initiative to improve the process management and to increase the maturity level. As previously mentioned, research concerning process management maturity in Serbia is rare, and so far it has not been possible to draw certain conclusions, concerning factors which have the greatest influence on making process management more mature.

The results of this research indicate very low level of process management maturity in the Serbian economy. Process awareness and measurement itself, as one of the elements, has the highest average mark (overall observed, for all groups of organizations), indicating that this element is close to the third maturity level. However, this is not enough, since Process awareness and measurement is followed only by People management, concerning maturity level. All other elements, especially IT and Culture, are at lower maturity level. If mutual correlation between those elements is added into analysis, than those two elements (IT and Culture) may be considered as significant bottleneck for further maturity level improvement (concerning individual elements and overall maturity level). This can be also concluded based on dominant elements analysis, which confirms that Culture and IT are the only elements whose influence is different in developing and developed countries. On one hand, in Serbia as developing country, IT appears twice as dominant an element (for reaching the second and the fifth maturity level), while on the other hand, culture, which should be transformed during the first stage (and which should be critical for reaching second maturity level), gains the importance at the fourth or for reaching the fifth maturity level. One can therefore conclude that culture is a significant constraint for the implementation of process based management in the enterprises in Serbia. Possible reasons for this might be limited financial resources (concerning IT) and/or consequences proceeding form a long period of socialism and socially-owned property (concerning Culture). Regarding this, it might be said that managers in the enterprises in Serbia should pay more attention to IT and Culture, as BPMM model elements. This further means that they may introduce training programs for providing IT knowledge and developing a system of values and beliefs which will improve the culture of the organization.

According to the research results, it seems that process orientation, which is more technical and mechanistic, is present to a certain extent in organizations in Serbia, but it 
should be turned into a process management, as a more holistic approach. This once again confirms that contemporary management concepts and models cannot be simply embedded into business, but rather adapted to appropriate context and culture. More specifically, managers have to know that the introduction of new concepts and models, such as BPMM model, assumes continual process of changing context, culture, structure and the model itself.

The research results also indicate that higher maturity level of process management model elements may be connected to higher business performances, for example, profit per employee. According to the analysis based on SAW method, the organizations that achieved higher profit per employee are the ones where process management model elements are at a higher maturity level. This conclusion is aligned with other research results. For example, according to some authors (Palmberg 2010, p. 109), the implementation of the process management model enables cost savings (among other results, such as increased understanding among employees regarding strategies and customer needs, standardization of work procedures, more effective use of employees, sharper economic control and easier to drive improvement), which, when other conditions remains the same, lead to profit increase. Research by other authors confirms that business process orientation has a positive influence on organizational performance, precisely on financial performance, but indirectly through non-financial performances (Bosilj-Vukic, Indihar-Štemberger 2008). Therefore, the results of the research may be accepted as representative, since they correspond to other research results. In this sense, these results might be interpreted as a signal for managers in Serbia to facilitate process management development. On the other hand, these results might be used as a kind of a roadmap of how to do that, indicating which elements managers should focus the attention on in order to provide a balanced development of process management elements, since it is the only proper way to increase the overall process management maturity level.

The main limitation of this research is the constrained possibility for benchmarking the results concerning Serbia with other developing countries, since research indicating process management maturity levels in developing countries is very rare and usually not comprehensive. Therefore, future research results from other developing countries may be useful in assessing the validity of this research results and, possibly, as justification of the findings indicated in this paper. Also, future research should include more detailed analysis about factors contributing to the differences between developed and developing countries concerning BPMM elements and their influence on maturity levels and business performances.

\section{Acknowledgements}

I would like to thank American Councils for International Education, which is in charge for administration of Junior Faculty Development Program (JFDP), a program of Bureau of Educational and Cultural Affairs of the United States Department of State, for supporting my stay in the United States (Oregon, Salem, Willamette University: Atkinson Graduate School of Management). 


\section{References}

Andjelkovic Pesic, M.; Jankovic Milic, V.; Andjelkovic, A. 2012. Business process management maturity model - the level of maturity in the enterprises in Serbia, Economics of Enterprise 60(3-4): 190-198.

Andjelkovic Pesic, M.; Jankovic Milic, V.; Stankovic, J. 2012. Significance of business quality management for increasing competitiveness of Serbian economy, Serbian Journal of Management 7(1): 149-170.

Andjelkovic Pesic, M. 2009. Business Process Management Maturity Model and Six Sigma, An Integrated Approach for Easier Networking [online], [cited 16 December 2012]. Available from Internet: http://emnet.univie.ac.at/uploads/media/Andjelkovic-Pesic_01.pdf

Bazhenova, E.; Taratukhin, V.; Becker, J. 2012. Impact of information and communication technologies on business process management on small and medium enterprises in the emerging countries, in N. Aseeva, E. Babkin, O. Kozyrev (Eds.). Emerging topics in business informatics research. Paper presented at $11^{\text {th }}$ International Conference on perspectives in business informatics research, National Research University - Higher School of Economics and Faculty of Business informatics and applied mathematics, Russia, 24-26 September, 2012, Nizhny Novgorod, Russia, 65-74.

Bosilj-Vukšic, V.; Indihar-Štemberger, M. 2008. The impact of business process orientation on financial and non-financial performance, Business Process Management Journal 14(5): 738-754. http://dx.doi.org/10.1108/14637150810903084

Business Process Management for developing countries. (n.d.) [online], [cited 12 December 2012]. Available from Internet: http://www.bpm.scitech.qut.edu.au/research/studentprojects/ BPM_Modelling_Projects_2010.pdf

De Bruin, T.; Freeze, R.; Kaulkarni, U.; Rosemann, M. 2005. Understanding the main phases of developing a maturity assessment model, in B. Campbell, J. Underwood, D. Bunker (Eds.). Proceedings from $16^{\text {th }}$ Australasian Conference on Information Systems ACIS, Paper presented at $16^{\text {th }}$ Australasian Conference on Information Systems, New South Wales, 30 November -2 December, 2005, Sydney, Australia, 8-19.

De Bruin, T.; Rosemann, M. 2005. Towards a business process management maturity model, in D. Bartmann, F. Rajola, J. Kallinikos, D. Avison, R. Winter, P. Ein-Dor, et al. (Eds.). Proceedings of the $13^{\text {th }}$ European Conference on Information Systems ECIS 2005, Paper presented at $13^{\text {th }}$ European Conference on Information Systems, 26-28 May, 2005, Regensburg, Germany, 26-28. Deming, W. E. 1982. Out of the crisis. Cambridge, MA: MIT Press.

Fisher, M. 2004. The business process maturity model: a practical approach for identifying opportunities for optimization, BPTrends 9: 1-7.

Forslund, H.; Jonsson, P. 2009. Obstacles to supply chain integration of the performance management process in buyer-supplier dyads: the buyers' perspective, International Journal of Operations \& Production Management 29(1): 77-95. http://dx.doi.org/10.1108/01443570910925370

Gulledge Jr, T. R.; Sommer, R. A. 2002. Business process management: public sector implications, Business Process Management Journal 8(4): 364-376.

http://dx.doi.org/10.1108/14637150210435017

Hammer, M. 2007. The process audit, Harvard Business Review 4: 1-17.

Hammer, M.; Champy, J. 1993. Reengineering the corporation: a manifesto for business revolution. New York: Harper Business.

Harmon, P. 2008. Governance and maturity, BPTrends 7: 1-2.

Hertz, S.; Johansson, J. K.; De Jager, F. 2001. Customer-oriented cost cutting: process management at Volvo, Supply Chain Management 6(3): 128-141. http://dx.doi.org/10.1108/13598540110399174 Humphrey, W. 1988. Characterizing the software process: a maturity framework, IEEE Software 2(5): 73-79. http://dx.doi.org/10.1109/52.2014 
Hung, R. Y. Y. 2006. Business process management as competitive advantage: a review and empirical study, Total Quality Management \& Business Excellence 17(1): 21-40.

http://dx.doi.org/10.1080/14783360500249836

Juran, J. 1992. Juran on quality by design: the new steps for planning quality into goods and services. New York: Juran Institute, The Free Press.

Lee, J.; Lee, D.; Kang, S. 2007. An overview of the business process maturity model (BPMM), in Advances in web and network technologies, and information management. Springer Berlin Heidelberg, 384-395.

Lewellyn, N.; Armistead, C. 2000. Business process management: exploring social capital within processes, International Journal of Service Industry Management 11(3): 225-243.

http://dx.doi.org/10.1108/09564230010340751

Lockamy, A.; McCormack, K. 2004. The development of a supply chain management process maturity model using the concepts of business process orientation, Supply Chain Management: an International Journal 9(4): 272-278. http://dx.doi.org/10.1108/13598540410550019

Maull, S.; Tranfield, D.; Maull, W. 2003. Factors characterising the maturity of BPR programmes, International Journal of Operations \& Production Management 23(6): 596-624.

http://dx.doi.org/10.1108/01443570310476645

McCormack, K. et al. 2009. A global investigation of key turning points in business process maturity, Business Process Management Journal 15(5): 792-815.

http://dx.doi.org/10.1108/14637150910987946

Neubauer, T. 2009. An empirical study about the status of business process management, Business Process Management Journal 15(2): 166-183. http://dx.doi.org/10.1108/14637150910949434

Palmberg, K. 2010. Experiences of implementing process management: a multiple-case study, Business Process Management Journal 16(1): 93-113. http://dx.doi.org/10.1108/14637151011017967 Power, B. 2007. Michael Hammer's process and enterprise maturity model, BPTrends 7: 1-4.

Ravesteyn, P.; Zoet, M.; Spekschoor, J.; Loggen, R. 2012. Is there dependence between process maturity and process performance?, Communications of the IIMA 12(2): 65-80.

Röglinger, M.; Pöppelbuß, J.; Becker, J. 2012. Maturity models in business process management, Business Process Management Journal 18(2): 328-346.

http://dx.doi.org/10.1108/14637151211225225

Rosemann, M.; De Bruin, T. 2005. Application of a holistic model for determining BPM maturity, BPTrends 2: 1-21.

Rosemann, M.; De Bruin, T.; Hueffner, T. 2004. A model for business process management maturity, in Proceedings of the 15th Annual Australasian Conference on Information Systems (ACIS) 2004, 1-3 December, 2004, Association for Information Systems, Hobart, Tasmania [online], [cited 15 November 2012]. Available from Internet: http://eprints.qut.edu.au/25626/

Shewhart, W. A. 1939. Statistical method from the viewpoint of quality control. Washington, DC: Graduate School of the Department of Agriculture.

Skalle, H.; Ramachandran, S.; Schuster, M.; Szaloky, V.; Antoun, S. 2009. Aligning business process management, service-oriented architecture, and Lean six sigma for real business results [online], [cited 19 January 2013]. IBM Redbooks. Available from Internet: http://www.redbooks. ibm.com/abstracts/redp4447.html

Sommerville, I.; Ransom, J. 2005. An empirical study of industrial requirements engineering process assessment and improvement, ACM Transactions on Software Engineering and Methodology (TOSEM) 14(1): 85-117. http://dx.doi.org/10.1145/1044834.1044837

Spanyi, A. 2004. Beyond process maturity to process competence, BPTrends 6: 1-5. 
Staples, M.; Niazi, M. 2008. Systematic review of organizational motivations for adopting CMMbased SPI, Information and Software Technology 50(7): 605-620.

http://dx.doi.org/10.1016/j.infsof.2007.07.003

Triantaphyllou, E. 2000. Multi-criteria decision making methods: a comparative study. Boston, MA: Kluwer Academic Publishers.

Trochim, W. M.; Donnelly, J. P. 2006. The research methods knowledge base. 3rd ed. Mason, $\mathrm{OH}$ : Thomson Custom Publishing.

Weber, V.; Curtis, B.; Gardiner, T. 2008. Business Process Maturity Model Version 1.0 [online], [cited 10 November 2012available from Internet: http://www.omg.org/spec/BPMM/1.0/PDF/

Wisniewski, M. 2006. Quantitative methods for decision makers. New York: Prentice Hall.

Wolf, C.; Harmon, P. 2012. The state of business process management [online], [cited 23 January 2013]. BPTrends. Available from Internet: http://www.bptrends.com/surveys_landing.cfm

Wu, Z.; Christensen, D.; Li, M.; Wang, Q. 2006. A survey of CMM/CMMI implementation in China, in Unifying the Software Process Spectrum. Springer Berlin Heidelberg, 507-520.

Zafiropoulos, C.; Vrana, V. 2008. Service quality assessment in a Greek higher education institute, Journal of Business Economics and Management 9(1): 33-45.

http://dx.doi.org/10.3846/1611-1699.2008.9.33-45

\section{APPENDIX}

\begin{tabular}{|c|c|}
\hline \multirow{5}{*}{$\begin{array}{l}\text { Strategic } \\
\text { alignment }\end{array}$} & Top management supports process orientation \\
\hline & Work is performed in a process oriented manner \\
\hline & Strategy is communicated through organization \\
\hline & Process architecture is aligned with strategy \\
\hline & Process improvement is aligned with strategy \\
\hline \multirow{5}{*}{$\begin{array}{l}\text { Process awareness } \\
\text { and measurement }\end{array}$} & Process owners are identified \\
\hline & Customers and suppliers for each process are identified \\
\hline & Process measures are used beside process output measures \\
\hline & Process control is based on measurement \\
\hline & Processes are continually improved \\
\hline \multirow{5}{*}{$\begin{array}{l}\text { Information } \\
\text { technology }\end{array}$} & IT is used for process design \\
\hline & IT is used for process execution \\
\hline & IT is used for process control \\
\hline & IT is used for process improvement \\
\hline & IT is used for project management \\
\hline \multirow{5}{*}{$\begin{array}{l}\text { People } \\
\text { management }\end{array}$} & Roles, tasks and responsibilities are defined \\
\hline & People have appropriate knowledge and skills for performing tasks \\
\hline & People are involved with improvements \\
\hline & People are provided with necessary training and development \\
\hline & Along the process there is communication and collaboration \\
\hline \multirow{5}{*}{ Culture } & People fill responsible for changes introduction \\
\hline & People share values and believes concerning process orientation \\
\hline & People share attitudes and behaviours concerning process orientation \\
\hline & People act like leaders for tasks they perform \\
\hline & Processes are base for establishment of social networks \\
\hline
\end{tabular}


Marija RADOSAVLJEVIC (earlier Andjelkovic Pesic) is a Visiting Professor at Willamette University, Atkinson Graduate School of Management, Oregon, and Assistant Professor at the University in Nis, Serbia. She participated in few projects concerning process and quality management and was a researcher at the University for Economics and Business Administration, Vienna, Austria. Her key interest areas are: quality management and process management. So far, she has published more than 100 papers in journals and proceedings from the conferences and 4 monographs. 